\section{Digitalization: The Way to Tourism Destination's Competitive Advantage (Case Study of Indonesia Marine Tourism)}

\section{Diaz Pranita}

Tourism Department of Vocational Program, Universitas Indonesia

\section{Abstract}

This article is a conceptual paper that proposes the importance of digitalization in marine tourism destination in order to significantly improve its competitive advantage. The digitalization should become a new capability as it supports the activities of value co-creation amongst the stakeholders including the customers. Digitalization will create resource integration, value platform and information-sharing models, while the pre-requisites for the success of its implementation are developing digital strategy, leadership and culture. National tourism digitalization movement, appoint seaports as leader in digital transformation, encourage collaboration intra- and inter-destination, and conduct intensive digital socialization and training.

Keywords: digitalization, digital capability, value co-creation, digital transformation

Received: 8 June 2018

Accepted: 17 July 2018

Published: 8 August 2018

Publishing services provided by

Knowledge $\mathrm{E}$

(c) Diaz Pranita. This article is

\section{Background}

distributed under the terms of

the Creative Commons

Attribution License, which

permits unrestricted use and

redistribution provided that the

original author and source are credited.

Selection and Peer-review under the responsibility of the 2nd ICVHE Conference Committee.

\section{G OPEN ACCESS}

As the largest archipelagic country which possesses more than 13,000 islands and $2 / 3$ of its area is water, developing and managing Indonesia as tourism destination is not a simple task. This situation is intensified with the high variation of the level of infrastructure, tourism services and development, as well as human resource quality in the destinations.

There are many suggestions on how to develop of marine tourism and the most popular is by employing sustainable tourism or community based tourism as the most trusted strategies ([21]; Manante, 2010), however the main issue for the success of tourism development is collaboration, integration, and synergy amongst stakeholders which made tourism as a complex system [7], a holistic network of stakeholders connected in experience environment (Tussadiyah \& Zach, 2013).

As we are now facing a new economy -the experience and sharing economy [17], the challenge of marine tourism destination is how to stage best experience for the 
customers through their products and services [12]. The service excellence that was pursued by every organization and business entity, has now become the very basic attributes of a product, while customers now seek the best experiences that are very personalized and available in real time [3]. The experience economy has also change customers' roles as very active actors to determine experiences that they wish to have, and that they demand for high involvement and engagement in the creation of their own experiences from the ideation to the consumption stages [18]. It is the rapid development of digital technology that has made the very personalized products and services while enabled customers to co create their unique experiences by mixing and matching different products and services from different companies [3]. It has also turned businesses to change their paradigm, business processes and even business models in order to serve their customers. Consequently, digital technology has resulted a disruptive business environment in all industries including tourism [7].

In tourism industry, digital technology has made a lot of travel bureau fold down as its function replaced by online travel agencies and other online booking systems in a way that has never been imagined before [22]. Today's customers demand on high involvement in creating their experience in real time, which can be easily materialized by digital platform [24]. Other important factor resulted by the digitalization is the connectedness of customers, not only to businesses but also to other customers. Digital technology has encouraged customers using their advocate roles on the products or services. Businesses has less control to customers than before, and to succeed they should conduct coopetition strategy or 'cooperate and compete' at the same time [10]. This create sharing economy. Internet has forced business environment to share not only information but also resources and infrastructure that lead to a transparency [16].

This situation is also faced by tourism destinations in the world. Digital technology has made all destinations, small or large, compete one another in global market. There is no product without customers and the scattered customers become accessible. However this could happen only if they utilize digital technology. Digitalization today has made many tourism industries facing new stage of development such as smart destination, smart cities, smart airports, smart seaports, smart hotels and other industries that adopt digital transformation [7, 8].

As contrast to other destination in the world, Indonesia marine destinations are remote, under development, traditionally managed and far from the digital technology touches. It is a hard struck that compared to Singapore, Malaysia and Thailand, there are some remote areas are not yet equipped with internet connection while other countries has been facilitated with $4 \mathrm{G}$, in many areas in Indonesia the broadband 
network are $2 \mathrm{G} / 3 \mathrm{G}$ and marine facilities are lag behind. It is a bitter fact that the development of marine tourism has just launched by the new precedency in 2014 while Malaysia has begun in 20 years earlier and so are Thailand and Singapore that are known as the hub of marine tourism in South East Asia.

To develop and improve its marine tourism, the government has deregulate its policy and regulation especially for the ease entry of foreign yachts to Indonesia, create Internet-based application to register yachts Yocht_ERS that can be used by yachties to get Vessel Declaration that enable the yachts enter and stay in Indonesian waters for 3 years, and develop 100 tourism ports. What interesting is the intention of government to connect each area in Indonesia especially the cross borders by broadband village projects to improve connectivity. Therefore, this article proposes digitalization as the answer for marine tourism destinations to improve competitive advantage significantly.

\section{Tourism and Digitalization}

Tourism is a bundle of services required by tourists away from home and is considered as an information intensive sector. According to Buhalis et al. (2013), in tourism, decision formation is associated with extensive, dynamic information search. Not only do customers gather information to make choices but also to compare choices they have already made. Therefore, relationship between information and communication (ICT) and tourism has been very close since the prevalence of information in tourism sector. Since the introduction of computer reservation systems in the early 1960s, ICT has become a fundamental part of the travel industry and now, with the prevalence of Internet-enabled devices, it forms a significant part of tourists' decision process.

\subsection{Digitization and digitalization}

There are two terms most common in society, Digitization and Digitalization. According to Bandi, Angadi \& Shivarama (2015), digitization in simple definition is automation or the conversion of analog source material into a numerical format. Digitization is mostly the automation of existing manual and paper-based processes. While digitalization is the use of digital technology to change a business model and provide now revenue and value producing opportunities [6]. Digitalization is the process of moving to become a digital business, realize a digital workplace, creating a digital supply chain, transform 
business process and create environment for digital business, whereby digital information is at the core [4].

\subsection{Digital technology as new destination capabilities}

Dickinson et al. (2012) proposes that tourism destination today must possess digital capability. Digital capability is a cross functional proficiency in the processes, practices and customer connections enabled by digital media and infrastructure. There are four dimensions of utilization of digital technology: the capability to provide destination information, the capability to share information, context awareness capability and tagging capability.

The capability to share information consists of destination interpretation, provision of travel schedule, and provision of static map to relocate attraction, accommodation and tourists facilities. Sharing information capabilities must be in two ways from the destination and its stakeholders as suppliers and the tourists as customers. Through digital technology capability, the destination will obtain and manage big data which was from the past and in real time as well as prediction for facility utilization in future. Context awareness capabilities are the provision of attraction or facilities proximity, the ability to provide travel information directly (real time), and the ability to specified user's travel itineraries. While tagging capability is the ability to record information for travelers for future usage.

As Indonesia marine tourism in its infancy stage to the utilization of digital technology as the new destination capabilities, digital transformation will not be an easy task as the local tourism industries and community are mostly computer illiteracy. The digital village project is a breakthrough and could be utilized in parallel with the digitization of processes. There are a lot of works to be done and the support from multi stakeholders is a must. Ministry of Communication and Information together with the telecommunication companies should work together to develop digital villages and digital platform. The Ministry of Tourism, local government tourism industries and local communities must work together to manage the contents of digital platform including the updates as well as create new digital culture in the destination. While academia must support in educating and provision of local talents.

The main problem is that digital technology mastery which was proposed by Dickinson et al. (2012) was the latest 3.0 to 4.0 technology, the internet of things (IOT) era. While the marine destinations in Indonesia have not even mastered the 1.0 web development and updates or the interactive 2.0 technologies. The other challenge is 
the qualification of human resources in the remote destinations. Many of them have not yet been familiar with digital technology or devices. This challenge is worsen by the low buying power of community to obtain computer devices and smart phone as the basic tool of digital technology.

To fill in the technology and human resource gaps are through provision of devices, intensive training and education, as well as national digital movement.

\subsection{Digitalization and value co-creation}

According to Shulga, Busser \& Henthorne (2015), digitalization has transform value creation process that was performed by producers to customers co create value together with company and its supply chains from the design stage of product, the production and consumption stages. It has also transformed the innovation that was initially in the internal company's domain (inside company) to external customer environment (outside company).

In addition, Akaka, Schau \& Vargo (2013) states that customers are connected to each other and they are connected to customer community platform. They share their experiences with their consumption and they even advocate their experiences to other customers. This situation has turn a company has less power to control customers and it is likely external communication from a company influence their buying decision as before [16]. Digitalization provides choices for customers while the production and consumption processes are determined by customers at their preferred time and formats. Value co creation improves customer satisfaction and turn customers as designer and co-producer.

Prahalad \& Ramaswamy (2004) proposed DART Model to enable value co creation, which consists of interactive dialogue mechanism in each value chain stage, access to company's resources including the supply chains, customer's opportunities to compare risks and benefits when consuming the products (risk assessment) and information transparency. Later, Coussement \& Teague (2013) and Schiavone (2014) proposed DARTT Model, adding technology management as other dimension to consider in value co creation.

Thus, digitalization transform value creation process, improve customer and stakeholder's participation as well as collaboration amongst stakeholders. Integration is the keyword for digitalization which is the important requirement of value co creation.

The impact of digitalization and value co creation is: 
a. Resource Integration

Value co creation views all actors as resource integrators [25]. The reasons are because any resource obtained by an actor must be combined or bundled with other resources to be useful or valuable, and innovation is often the result of recombining existing resources for new service exchange and innovation opportunities. Firms and customers integrate resources in different ways. Firms integrate market resources, individual resources, and public resources using operating platforms. Customers integrate social network resources and individual resources (their knowledge) to participate in value co-creation.

b. Value Platform

Kijima et al. (2012) stated that value orchestration platform is a service system where co creation process and interaction of customers and providers occur to co create new values. The goal is to promote innovation and increase productivity. Rintamaki et al. (2007) identifies four layer of value, namely economic value, functional value, emotional value and symbolic value which reflect the spectrum from utilitarian to hedonic value. Emotional and symbolic value may be the true drivers for customer's decision-making while economic and functional value are used for argumentation.

Value platform concerned with methods to involve appropriate customers and providers in the platform and to vitalize interactions between customers and providers. Hence, strategies for the platform to attract and involve customers and providers to maximize profit are crucial. Indeed, one of the advantages of an online value orchestration business such as e-commerce is that they have no limitations on the number of customers who can participate.

A cycle of Sympathize, Identify, Participate, and Share and Spread (SIPS) is useful for identifying how customers and providers become interested in a platform. It generates interest among customers and the provider toward co-experience and co-definition phases.

SIPS proposes that the trigger for customers and providers to become interested in a service system is their having big data platforms represent an important channel for firms to co-create value with customers.

\section{c. Resources Sharing}

Digitalization has brought sharing and exchanging assets into online platforms as intermediary (European Commission, Chapter 4). Big data creates platforms 
to enhance the efficiency and effectiveness of service exchange by making resources liquid, increasing resource density, and facilitating easy access to appropriate resource bundles. According to Blix (2016) there three types resources sharings from value co creation: knowledge sharing, physical resources sharing and services sharing.

Knowledge sharing makes stakeholders have information and tools to interpret information and can help themselves to consume in a simpler and cheaper way. Physical resources sharing optimize the utilization of idle resources to be available on market thus minimizing waste. Sharing of services enable small companies to provide specialized services which are cheaper, faster and easier.

\subsection{Pre-requisition of digital transformation}

To ensure the success of digital transformation, businesses must fulfil the pre requirement on the organization level: focus on digital strategy, leadership and culture.

\section{a. Digital Strategy}

Digital strategy means that the top management should embrace digital throughout the organization value chains and develop clear direction and commitment throughout digitalization. Everyone has to understand how each channel operates and how the channel interconnects.

The strategy formulation begins with formulation of strategy in corporate, business and functional levels. The strategy should be translated into organization's vision, mission, objectives, goals, policies and processes, as well as the key success indicators. Digital strategy is formal lever of changes [13].

b. Digital Leadership

Digital leadership is mostly the informal lever of changes. It is the most important elements to ensure the digital implementation throughout the organization. The important issues of digital leadership is that top executives must show $100 \%$ commitment in their words and actions. The top executive not just fully support and telling the organization but actually drive the adoption of digital culture. Brabin \& Clayton (2016) mention that digital transformation requires leaders who are willing and able to leverage digital to innovate, fail fast and drive value in an ambiguous context.

c. Digital Culture 
According to Harshak, Schmaus \& Dimtrova (2013), company culture gives organization its personality and shapes both its internal processes and the way it is seen by the outside world. Culture has an intangible quality that requires sensitive stimulating and precise targeting of new key behavior in formal and informal way, so the culture can change itself. To change culture is to focus on the way people act on a day to day basis.

\section{Discussion}

Digital transformation will determine future and long term viability of every tourism destination. The Ministry of Tourism of Indonesia has determined three focus strategies to develop its tourism: digitalization, homestay development and connectivity, then the development of marine tourism destination should comply with the direction. Solutions to the initial digitalization transformation of Indonesia marine tourism destination as follows:

\subsection{Develop national digitalization movement}

As an initial digitalization program, Ministry of Tourism has launched Indonesia Travel Exchange (ITX) as the digital platform to integrate the destinations, industries and all tourism stakeholders national-wide.

Although marine tourism is still in its infancy, however the grand strategy has provide direction that marine destinations must follow and participate in the process. It is highly suggested that the Ministry of Tourism deploys its digital policy to provincial and local tourism offices as well as encourages a public, private and people to collaborate and synergy in developing a digitized thematic tourism products to reach a specific target market while integrate them with ITX as the digital platform.

\subsection{Appoint seaports as the leader to create value platform}

Beside ITX, airports in Indonesia has committed to transform its operational digitally and develop digital platform to integrate the related and required services. The airport's digital platform is also promoting tourist destinations and businesses. However, as Indonesian archipelago consists of 13,000 islands while its dimension is $85.000 \mathrm{sqm}$, it is highly recommended that seaports initiated digital transformation not only to optimize their operations but also support marine tourism destinations to global markets 
since airports can only reach large cities and destinations, while seaports can reach the most dispersed and remote destinations.

Digital Ports is not considered something new as many airports are now in progress toward smart airport to integrate and customers demand. The consideration is because seaports are united in a formal government owned company which are likely possess better talents, adequate funding and influence other stakeholders better than other entities in marine tourism.

\subsection{Encourage collaboration with intra- and inter-destination stakeholders}

Digitalization require high collaboration between stakeholders including customers and customers' communities. On the other hands, digitalization also supports and enables collaboration not only intra destination or inter destination but also in global market. The collaboration intra destination should be executed mostly in defining business processes, roles and contribution of each stakeholders to the collaboration platform. The collaboration and synergy should be covered multi stakeholders: business players in marine tourism destination as enabler, local community as accelerator, central and local government as regulator, academia as conceptor as well as media as expander.

\subsection{Intensive digitalization socialization and training}

As the variation of human resources arises, intensive socialization and trainings to acquiring new talents in digital technology are priorities. To materialize this, collaboration with telecommunication, digital companies and campus is an important aspects to carry out.

The initial digital transformation should be followed by the fully integrated digitalization on destination and the industries while at the same time educate people and other stakeholders so that digital culture emerges in the destination and become daily practices.

\section{References}

[1] Akaka, Hope Jensen Schau, Stephen L. Vargo, (2013), The Co-Creation of Valuein-Cultural-Context, in Russell W. Belk, Linda Price, Lisa Peñaloza (ed.) Consumer Culture Theory (Research in Consumer Behavior, Volume 15) Emerald Group 
Publishing Limited, pp.265 - 284

[2] Bandi, Shekappa and Angadi, Mallikarjun and Shivarama, J. Best Practices in Digitization: Planning and Workflow Processes., 2015. In International Conference on the theme 'Emerging Technologies and Future of Libraries: Issues and Challenges', Gulbarga University, Gulbarga, Karnataka, January 30-31, 2015.

[3] Binkhorst, Esther, 2009, The Co Creation Tourism Experience, Journal of Hospitality Marketing \& Management, Special Issue: The Marketing of Hospitality and Leisure Experience, Vol. 18, Issue 2-3, Taylor \& Francis.

[4] Blix, Marten., 2015, The Economy and Digitalization: Opportunities and Challenges, Confederation of Swedish Enterprise.

[5] Brabin, Paul \& Andy Clayton, 2016, Decoding Digital Leadership, Deloitte MCS Ltd.

[6] Brennen, J. S. and Kreiss, D. 2016. Digitalization. The International Encyclopedia of Communication Theory and Philosophy. 1-11.

[7] Buhalis, D., \& Amaranggana, A. (2013). Smart tourism destinations. In Information and Communication Technologies in Tourism 2014 (pp. 553-564). Springer International Publishing.

[8] Buonincontri, Pitera \& Roberto Micera, 2016, The Experience Co-creation in Smart Tourism Destinations: A Multiple Case Analysis of European Destinations, Information Technology and Tourism (2016) 16: 285.

[9] Coussement, Martha Anne., Thomas J. Teague, 2013, The new customer-facing technology: mobile and the constantly-connected consumer, Journal of Hospitality and Tourism Technology, Vol. 4 Issue 2 pp. 177-187

[10] Della Corte, Valentina \& Massimo Aria, 2016, Coopetition and Sustainable Competitive Advantage. The Case of Tourist Destination, Tourism Management 54 (2016) 524-540, Elsevier Ltd.

[11] Dickinson, Janet E., Karen Ghali, Thomas Cherrett, Chris Speed, Nigel Davies \& Sarah Norgate, 2014, Tourism and the smartphone app: capabilities, emerging practice and scope in the travel domain, Current Issues in Tourism, 17:1, 84-101.

[12] Gronroos, Christian \& Paivi Voima, 2011, Making Sense of Value and Value Cocreation in Service Logic, Working Papers, Hanken School of Economics, ISBN 978952-232-157-2, Helsinki 2011.

[13] Harshak, Ashley., Benedikt Schmaus and Diana Dimitrova, 2013, Strategy\&, Booz and Company.

[14] Kijima, Kyoichi., Timo Rintamki and Lasse Mitronen, 2012, Value Orchestration Platform: Model and Strategies, Naples Forum Service, Italy. 
[15] Manente, Mara, 2008, Destination Management and Economic Background: Defining and Monitoring Local Tourist Destinations, Central Paper, Session 4, Tourism Destination management, CISET, University of Venice, Italy.

[16] Melis, Giuseppe., Scott McCabe, Giacomo Del Chiappa, 2015, Marketing Places and Spaces, 75-89, Emerald Insight.

[17] Pine II, B. Joseph \& James H. Gilmore. 1999. Welcome to the Experience Economy. Harvard Business Review July-August 1998.

[18] Piller, Frank T. and Ihl, Christoph and Vossen, Alexander, 2010, A Typology of Customer Co-Creation in the Innovation Process (December 29, 2010).

[19] Prahalad, CK, Vankat Ramaswamy, 2004, Co Creating Unique Value with Customers, Strategy \& Leadership, Vo. 32 No. 3, 2004, Emerald Group Publishing

[20] Rintamaki, T and H. Kuusela, 2007, Identifying Competitive Customer Value Propositions in Retailing, Managing Service Quality, 17 (6), 621-634.

[21] Ritchie J.R. Brent, and Geoffrey I. Crouch, 2010. A Model of Destination Competitiveness/sustainability: Brazilian Perspective. Published by CAB International, Oxfordshire, UK.

[22] Romina, Oricchio., Testa Silvia, Nicolo Costa., 2013, Niche Market Tour Operators and Mass Market Online Travel Agencies: The Case Study of U.S. Organized Tourism in Italy, American Journal of Tourism Research, Vol. 2 No. 1, 2013, 101-123.

[23] Schiavone, Francesco, Concetta Metallo and Rocco Agrifoglio, 2014, Extending DART Model for Social Media, International Journal Technology Management, Vol. 66, No. 4, 2014.

[24] Terblanche, N.S., 2014, Some theoretical perspectives of co-creation and coproduction of value by customers', Acta Commercial 14(2), Art. \#237

[25] Xie, Kang., Yao Wu, Jinghua Xiao, Qing Hu, 2016, Value Co-Creation between Firms and Customers: The Role of Big Data Based Cooperative Assets, Information \& Management No. 2916, www.elsevier.com. 